\title{
Processing of gender and number agreement in late Spanish bilinguals: A commentary on Sagarra and Herschensohn
}

International Journal of Bilingualism 17(5) 628-633

(C) The Author(s) 2013 Reprints and permissions: sagepub.co.uk/journalsPermissions.nav DOI: $10.1177 / \mid 3670069$ ||435693 ljb.sagepub.com

@SAGE

\section{Leah Roberts}

University of York, UK; Max Planck Institute for Psycholinguistics, The Netherlands

\section{Introduction}

Sagarra and Herschensohn's article examines English L2 learners' knowledge of Spanish gender and number agreement and their sensitivity to gender and number agreement violations (e.g. * $E l$ ingeniero presenta el prototipo *famosa/*famosos en la conferencia) during real-time sentence processing. It raises some interesting questions that are central to both acquisition and processing research. In the following paper, I discuss a selection of these topics, for instance, what types of knowledge may or may not be available/accessible during real-time L2 processing at different proficiency levels, what the differences may be between the processing of number versus gender concord, and perhaps most importantly, the problem of how to characterize the relationship between the grammar and the parser, both in general terms and in the context of language acquisition.

\section{Explicit and implicit knowledge}

S\&H report that although both their lower proficient and intermediate English L2 learners of Spanish were able to demonstrate adequate knowledge of Spanish gender and number in an independent grammar test, whether or not they could make accurate metalinguistic judgments in an off-line task and were sensitive to agreement discord during real-time processing depended on their general proficiency. The intermediate learners were able to assess successfully the ungrammaticality of gender as well as number disconcord and were also sensitive online to number and gender agreement violations. Furthermore, although the intermediates were not fully native-like, they performed similarly to the Spanish control group in that gender disconcord was overall more difficult to process than number disconcord, and animate nouns more difficult than inanimates. The less proficient group showed no effects at all for the gender conditions, and although they could judge the ungrammaticality of the items in the number concord conditions, they were not sensitive online to number agreement violations. One might disagree with the authors' claims that these results strongly go against fundamental difference accounts of L2 acquisition (e.g. Hawkins \& Franceschina, 2004) because their intermediate learners "start to show target-like processing 
and representation" (p.3) of parameterized functional features not available in their L1: one would need to test a much more advanced group showing native-Spanish-like performance to make such a strong claim (see Keating, 2009). Nevertheless, these data do show that the English learners can acquire some knowledge of Spanish gender concord, despite not having grammatical gender in their L1.

Interestingly, the results highlight the fact that the learner groups have different types of knowledge of the phenomena under investigation, as tapped into by the three different tasks. Critically, both groups were shown to know explicitly the gender of the nouns used in these experiments, but one could argue that only the intermediate learners had developed some implicit or automatized knowledge of gender concord, as captured during the real-time comprehension task. Furthermore, given that the lower proficiency group were not sensitive at all to number discord during real-time processing, this suggests the fact that English has number agreement (between demonstratives and nouns, e.g. these books, as well as between subject and verbs) helped them, but only in the grammaticality judgment task. However, it must be assumed that the lower proficient group indeed computed the dependency at some no doubt later stage in the processing of the experimental items because they were able to judge the number agreement items correctly. Taken together, these findings suggest that the immediate computing of agreement during online comprehension, even with phenomena that are available in one's L1, is a skill that must be developed with L2 experience. S\&H suggest that a working memory (WM) account such as that of Ullman (2005) can explain these findings - the less proficient learners have declarative knowledge that has yet to be proceduralized, and critically, this automatization can eventually take place, as shown by the performance of the intermediate learners.

\section{Gender versus number agreement processing}

S\&H's main conclusion is that "late learners of ungendered L1s can [begin to] gain native-like behavioral patterns of sensitivity to grammatical gender and number agreement violations" (p.1). The authors also claim an asymmetry both in the difficulty to acquire and in the computational cost of processing gender versus number agreement. Given that their English learners come from an ungendered language, but do have number agreement, one cannot use these L2 learner findings alone as evidence for the idea that gender agreement is in general a more complicated procedure than number agreement: this could just be a positive transfer effect. Furthermore, the indirect evidence of the findings that those intermediate learners of higher WM were more sensitive to gender but not number agreement violations (suggesting that gender taxes the system more) could also reflect the fact that the former is more difficult to learn than the latter specifically for a group with an ungendered L1. However, the authors' conclusions do receive support from other research, where evidence has been found of a similar asymmetry in processing performance and judgment accuracy observed in learners from a language background without grammatical or number agreement (Chinese) (Gillon-Dowens, Barber, Guo, Guo, \& Carreiras, 2011). It would be interesting to see whether a similar pattern is observed with a learner group with both number and grammatical gender (e.g. Italian). Also, Hopp (2010) found that German native speakers became less sensitive to gender disconcord than number when under processing pressure, again suggesting that gender is somehow more computationally costly than number processing.

Despite this accumulated evidence, it is still not clear exactly what underlies the differences between gender and number processing, but a look at other studies on the processing of gender/ 
number violations using the EEG methodology (to record electrical activity in the brain during comprehension) may help. First, it may be that it is not merely computing agreement in general that differs between number and gender, because it is only in the computing of agreement violations that differences are observed. Earlier studies have shown few differences at the earliest stage of detecting the anomaly in gender versus number agreement processing, rather it is differences at the later, reanalysis stage of processing that have been observed. For instance, both Spanish gender and number disconcord in a sentence context elicit an early left anterior negative (LAN)-going waveform thought to reflect the process of "noticing" the violation, but the positive-going component (P600) that follows has been observed later in time and larger in amplitude in response to gender versus number violations in native Spanish speakers (e.g. Barber \& Carreiras, 2005). Given that most researchers assume the amplitude of the P600 component reflects comparatively more difficulty in reanalyzing ungrammatical and/or integrating complex input, this suggests that the earliest stages of agreement processing are the same for number and gender, but that fixing a problem in concord requires more computational effort for gender than for number (and thus takes more time and shows up in measures of WM capacity differences, as shown in S\&H study). This is perhaps because, as $\mathrm{S} \& \mathrm{H}$ suggest, correcting a gender error requires revisiting the whole lexical item rather than merely recomputing a surface feature to be attached to the stem, as for number.

With regard to learners, given that gender disconcord seems to lead to lower accuracy scores in judgment tasks (see also Gillon-Dowens, Vergara, Barber, \& Carreiras, 2010), it may be that reanalyzing such ungrammaticalities is not always successful. The authors discuss whether this may be exacerbated because gender is processed in less depth than number, given the learners' genderless L1 background, on top of the computationally more demanding gender (re)processing. Support for such L1 influences comes from Sabourin and Stowe (2008) who report that Romance L1 learners of Spanish were sensitive to determiner-noun gender violations in Dutch (e.g. Het ${ }^{*}$ De kleine kind ...) in that such violations elicited an early negativity indicating that the learners had noticed the error, but unlike what is observed in the native speakers or the German L2 learners, there was no later P600 effect (see also Sabourin, 2003, but compare Tokowicz \& MacWhinney, 2005). Thus, if one assumes the reanalysis/reintegration functional explanation for the P600 component, it seems that only if the grammatical phenomenon is instantiated in their L1 are late L2 learners able to rectify the error during online processing (c.f., also Kaan \& Swaab, 2003). In fact, it appears that such later processing/reanalysis operations may be more difficult in general for L2 learners than native speakers, irrespective of the typological proximity of the L1 and the L2 (see Roberts, 2013, for an overview), but it would be interesting to test a more highly proficient late L2 learner group to see whether such learners could ever show nativelike brain responses to such violations if the phenomenon is not available in their L1.

\section{Grammar-parser relationship}

S\&H appear to view the pattern of L2 development of Spanish number and gender concord as a process of grammaticalization: explicit knowledge that gradually becomes automatized, and thus available for subconscious processing tasks. If viewed from this perspective, then such linguistic knowledge is on a continuum - depending on proficiency - from explicit to implicit. In this case, the lines between grammatical knowledge and parsing performance become blurred, rather than there being a clear-cut distinction, which S\&H appear to assume, like most L2 acquisition researchers working within a generative framework. That is, there is the (often implicit) assumption of a modular cognitive architecture, with a completely informationally encapsulated grammar and a separate set of parsing procedures that apply the grammatical knowledge to the input. This is of 
course one way to view the grammar-parser relationship (e.g. Frazier, 1978; Pritchett, 1992), but it is not the only way (e.g. the grammar $i$ s the parser: cf. Phillips, 1996; see Vasishth \& Lewis, 2006 , for an overview of symbolic models). The complexity of the problem of how best to characterize the grammar-parser relationship is illustrated in the $\mathrm{S \& H}$ article. It is not clear what it is that researchers assume learners need to acquire. For instance, the authors ask whether the learners can "gain the processing of gender" (p.4), which suggests that it is the parsing procedure specifically for computing gender agreement, as well as and separate from the "knowledge" of gender, that must be acquired, and that this is different from that of the processing of number agreement. But given that computing dependencies, whether between words or across clauses, is a critical property of the comprehension process in any language, and that English speakers must compute number agreement, this may not to be the most elegant solution. If one wants to maintain a separate grammar and parser, then it makes more sense for the computational (agreement) procedure to be the same, but the underlying (grammatical) knowledge required to perform the two to be different. If this is the case, then what must be learned is merely the language-specific gender feature - the computational procedure should be the same for any dependency in speakers of any language. If this is the case, how can we account for the findings reported above that gender processing appears to be different from number processing in native speakers? Another problem is that when it comes to the data, as the authors themselves note, it is "impossible to clearly dissociate representation from processing empirically" but that "implicit knowledge plays a role in computation" (p.29) particularly since one must process the input in order to make a grammaticality judgment, and at the same time, processing the input will be affected by a comprehender's grammatical knowledge.

In sum, (L1 and L2) acquisition researchers often assume a clear-cut relationship between the grammar and the parser, for instance, arguing that learners do or do not show evidence of competence of some grammatical phenomenon, with differences lying at the level of performance. However, the relationship needs to be made explicit, even though this will be problematic given the fact that the nature of the relationship between grammatical knowledge and parsing has been controversial in monolingual psycholinguistic research for some decades and critically, it is as yet unresolved. For instance, proponents of various parsing models (ranging from serial, often parallel models to those with a fully interactive, constraint-based architecture) must somehow reconcile the seemingly contradictory findings that although the parser respects grammatical distinctions in many cases (e.g. grammatical islands; reactivating only syntactically appropriate antecedents), some data show that the correct grammatical analysis can be overridden by semantically plausible interpretations (the dog was bitten by the boy) (van Gompel \& Pickering, 2007).

Resolving theoretical issues about the nature of the parser-grammar relationship becomes even more complex when adding to the mix questions relating to acquisition. That is, a learner's grammar is developing and so he or she must often encounter input that is ungrammatical in terms of what is permissible in his or her current interlanguage. On the other hand, such ungrammatical sentences must be parsed but with limited grammatical knowledge, which in turn can lead to a change in the grammar. However, this critical language learning mechanism is still somewhat of a mystery, and the question has received surprisingly little attention in the literature (for some suggestions, see e.g. Dekydtspotter et al., 2008, for L2; and Fodor, 1999; Trueswell \& Gleitman, 2007, for L1).

\section{Conclusion}

S\&H's article raises many important issues that researchers face faced when investigating L2 processing from a linguistic perspective, and/or language acquisition from a processing perspective. 
The results show that certain types of L2 knowledge may or may not be accessible during metalinguistic tasks and during real-time comprehension, depending on the levels of proficiency; and that this knowledge can be tapped into by different tasks to offer a more rounded picture of what "acquisition" means. These L2 data (together with other research) also add to the psycholinguistic findings on the processing of number and grammatical gender, and show how investigating L2 learners can tell us what is more and less easily learnable, and thus can shed light on interesting differences in the (processing of the) target language. Finally, S\&H face the thorny issue of the nature of the relationship between the grammar and the parser, which is controversial in the current (monolingual) psycholinguistic literature. Both L1 and L2 acquisition/processing researchers who are interested in parsing and learning face a real challenge in the future in the attempt to both characterize the nature of learners' knowledge and investigate how parsing the input during real-time processing can lead to the development of that knowledge.

\section{References}

Barber, H., \& Carreiras, M. (2005). Grammatical gender and number agreement in Spanish: An ERP comparison. Journal of Cognitive Neuroscience, 17, 137-153.

Dekydtspotter, L., Kim, B., Kim, H.-J., Wang, Y.-T., Kim, H.-K., \& Lee, J. K. (2008). Intermediate traces and anaphora resolution in the processing of English as a second language. In H. Chan, H. Jacob, \& E. Kapia (Eds.), Proceedings of BUCLD 32 (Vol. 1, pp. 84-95). Somerville, MA: Cascadilla Press.

Fodor, J. D. (1999). Learnability theory: Triggers for parsing with. In E. Klein, \& G. Martohardjano (Eds.), The development of second language grammars: A generative approach (pp. 363-406). Amsterdam, Netherlands: John Benjamins.

Frazier, L. (1978). On comprehending sentences: Syntactic parsing strategies (Doctoral dissertation). University of Connecticut, Storrs, CT, USA.

Gillon-Dowens, M., Barber, H., Guo, T., Guo, J., \& Carreiras, M. (2011). Gender and number processing in Chinese learners of Spanish-Evidence from event related potentials. Neuropsychologia, 49, 1651-1659.

Gillon-Dowens, M., Vergara, M., Barber, H. A., \& Carreiras, M. (2010). Morpho-syntactic processing in late L2 learners. Journal of Cognitive Neuroscience, 22, 1870-1887.

Hawkins, R., \& Franceschina, F. (2004). Explaining the acquisition and non-acquisition of determiner-noun gender concord in French and Spanish. In P. Prévost \& J. Paradis (Eds.), The acquisition of French in different contexts (pp. 175-206). Amsterdam, Netherlands: John Benjamins.

Hopp, H. (2010). Ultimate attainment in L2 inflectional morphology: Performance similarities between nonnative and native speakers. Lingua, 120, 901-931.

Kaan, E., \& Swaab, T. Y. (2003). Repair, revision and complexity in syntactic analysis: An electrophysiological differentiation. Journal of Cognitive Neuroscience, 15, 98-110.

Keating, G. D. (2009). Sensitivity to violations in gender agreement in native and nonnative Spanish: An eye-movement investigation. Language Learning, 59, 503-535.

Morgan-Short, K., \& Ullman, M. T. (to appear). Neurolinguistics. In S. Gass \& A. Mackey (Eds.), Handbook of second language acquisition. New York: Routledge.

Phillips, C. (1996). Order and structure (PhD dissertation). MIT, Cambridge, MA, USA.

Pritchett, B. (1992). Grammatical competence and parsing performance. Chicago, IL: University of Chicago Press.

Roberts, L. (2013). Sentence processing in bilinguals. In R. van Gompel (Ed.), Sentence processing: Current issues in language (pp. 221-246). London: Psychology Press.

Sabourin, L. (2003). Grammatical gender and second language processing (Groningen dissertations in linguistics, volume 42). CLCG, Groningen. 
Sabourin, L., \& Stowe, L. (2008). Second language processing: When are first and second languages processed similarly? Second Language Research, 24, 397-430.

Tokowicz, N., \& MacWhinney, B. (2005). Implicit and explicit measures of sensitivity to violations in second language grammar. Studies in Second Language Acquisition, 27, 173-204.

Trueswell, J. C., \& Gleitman, L. R. (2007). Learning to parse and its implications for language acquisition. In G. Gaskell (Ed.), Oxford handbook of psycholinguistics (pp. 635-356). Oxford, UK: Oxford University Press.

Ullman M. T. (2005). A cognitive neuroscience perspective on second language acquisition: The declarative/ procedural model. In: C. Sanz (Ed.), Mind and Context in Adult Second Language Acquisition: Methods, Theory and Practice (pp. 141-178). Washington, DC: Georgetown University Press.

Van Gompel, R.P.G., \& Pickering, M.J. (2007). Syntactic parsing. In G. Gaskell (Ed.), The Oxford handbook of psycholinguistics (pp. 289-307). Oxford, UK: Oxford University Press.

Vasishth, S., \& Lewis, R. L. (2006). Symbolic models of human sentence processing. In K. Brown (Ed.), Encyclopedia of language and linguistics (2nd ed.). Elsevier.

\section{Author biography}

Leah Roberts worked as a Scientific Staff Member in the Language Acquisition Group at the Max Planck Institute for Psycholinguistics between 2003 and 2011. She is currently Professor of Education, in the Centre for Language Learning Research at the University of York, UK. 
Copyright of International Journal of Bilingualism is the property of Sage Publications, Ltd. and its content may not be copied or emailed to multiple sites or posted to a listserv without the copyright holder's express written permission. However, users may print, download, or email articles for individual use. 